\title{
Sobre o viver em uma cidade/sociedade capacitista: tempos pandêmicos
}

\author{
On living in a capacitist city/society: pandemic times \\ Sobre vivir en una ciudad/sociedad capacitista: tiempos de pandemia
}

Recebido: 23/01/2021 | Revisado: 24/01/2021 | Aceito: 28/01/2021 | Publicado: 02/02/2021

\author{
Annibal Coelho de Amorim \\ ORCID: https://orcid.org/0000-0003-0157-4527 \\ Fundação Oswaldo Cruz, Brasil \\ E-mail: annibalamorim.fiocruz@gmail.com \\ Sônia Regina da Cunha Barreto Gertner \\ ORCID: https://orcid.org/0000-0003-3564-5039 \\ Fundação Oswaldo Cruz, Brasil \\ E-mail: soniacrescimento@gmail.com \\ Anna Paula Feminella \\ ORCID: https://orcid.org/0000-0003-0693-3517 \\ Escola Nacional de Administração Pública, Brasil \\ E-mail: anna.feminella.amy @gmail.com \\ Rita Louzeiro \\ ORCID: https://orcid.org/0000-0001-8124-985X \\ Universidade de Brasília, Brasil \\ E-mail: ritalouzeiro@yahoo.com.br
}

\begin{abstract}
Resumo
As imagens das cidades vazias mundo afora no início da Pandemia são fatos que passam a fazer parte de qualquer cenário analítico, teórico e prático e representam um desafio contemporâneo. Na mesma proporção, pensar sobre o viver em uma cidade/sociedade capacitista - antes, durante e depois da pandemia -, assemelha-se muito ao esvaziamento das salas de aula, o esvaziamento de direitos e das demandas de segmentos de pessoas com deficiência. Tão grave quanto esses "esvaziamentos" são aqueles que remetem aos conceitos que continuam a construir as barreiras - arquitetônicas, comunicacionais, atitudinais, socioculturais - em cidades, escolas, museus e espaços de lazer das cidades no III Milênio. O desafio de tematizar sobre o viver diferentes inacessibilidades cotidianas nas cidades tangenciam e suscitam discussões no plano ético-estético dos territórios existenciais das pessoas com deficiência. Interroga-se, em que medida, os profissionais que pensam e contribuem no planejamento urbano mantém conceitos que sustentam certos constructos de invisibilidade. O artigo propõe-se a sobrevoar a "paisagem das cidades" partindo de teorias das ciências críticas e da noção de direito do sujeito sanitário. Estariam os urbanistas do III Milênio pensando as cidades sem pensar nas pessoas que nelas habitam? E o debate técnico sobre acessibilidade é suficiente para contemplar as demandas por uma vida sem discriminação em razão de deficiência? O ensaio busca colaborar com o debate público sobre a necessidade de ações planejadas visando a superação do capacitismo com vistas à efetivação de políticas públicas.
\end{abstract}

Palavras-chave: Sujeito sanitário; Território existencial; Capacitismo; Sociedade.

\begin{abstract}
The images of empty cities around the world at the beginning of the Pandemic are facts that become part of any analytical, theoretical and practical scenario and represent a contemporary challenge. In the same proportion, thinking about living in a capacitist city / society - before, during and after the pandemic - is very similar to the emptying of classrooms, the emptying of rights and the demands of segments of people with disabilities. As serious as these "emptyings" are those that refer to the concepts that continue to build barriers - architectural, communicational, attitudinal, sociocultural - in cities, schools, museums and leisure spaces in the cities in the Third Millennium. The challenge of addressing the issue of living different daily inaccessibilities in cities touches and raises discussions on the ethical-aesthetic level of the existential territories of people with disabilities. It is questioned, to what extent, the professionals who think and contribute to urban planning maintain concepts that support certain constructs of invisibility. The essay proposes to fly over the "city landscape" starting from theories of critical sciences and from the notion of the right of the sanitary subject. Are the planners of the Third Millennium thinking about cities without thinking about the people who inhabit them? And is the technical debate about accessibility sufficient to contemplate the demands for a life without discrimination due to disability? This essay seeks to collaborate with the public debate on the need for planned actions aimed at overcoming capacitism in order to implement public policies.
\end{abstract}

Keywords: Sanitary subject; Existential territory; Capacitism; Society.

\section{Resumen}

Las imágenes de ciudades vacías alrededor del mundo al comienzo de la Pandemia son hechos que pasan a formar parte de cualquier escenario analítico, teórico y práctico y representan un desafío contemporáneo. En la misma 
proporción, pensar en vivir en una ciudad / sociedad capacitista -antes, durante y después de la pandemia- es muy similar al vaciamiento de aulas, el vaciamiento de derechos y las demandas de segmentos de personas con discapacidad. Tan graves como estos "vaciamientos" son los que se refieren a los conceptos que siguen construyendo barreras - arquitectónicas, comunicacionales, actitudinales, socioculturales - en las ciudades, escuelas, museos y espacios de ocio de las ciudades del Tercer Milenio. El desafío de abordar el tema de vivir diferentes inaccesibilidades cotidianas en las ciudades toca y suscita discusiones sobre el nivel ético-estético de los territorios existenciales de las personas con discapacidad. Se cuestiona hasta qué punto los profesionales que piensan y aportan al urbanismo mantienen conceptos que sustentan ciertos constructos de invisibilidad. El artículo propone sobrevolar el "paisaje de la ciudad" a partir de las teorías de las ciencias críticas y de la noción del derecho del sujeto sanitario. ¿Los urbanistas del Tercer Milenio piensan en las ciudades sin pensar en las personas que las habitan? ¿Y el debate técnico sobre accesibilidad es suficiente para contemplar las demandas de una vida sin discriminación por discapacidad? El ensayo busca colaborar con el debate público sobre la necesidad de acciones planificadas encaminadas a la superación del capacitismo con miras a implementar políticas públicas.

Palabras clave: Sujeto sanitario; Territorio existencial; Capacitismo; Sociedad.

\section{Introdução}

A análise sobre o viver em cidades inacessíveis ganha contornos dramáticos quando sobrepõe-se o contexto da maior crise sanitária desde a "gripe espanhola”. A eclosão e a propagação da Pandemia COVID-19 em grandes metrópoles ao redor do mundo, para além das profundas implicações sanitárias, impõe que temas ligados ao urbanismo sejam revisitados por pesquisas com perfil intersecional e/ou intersetorial.

Os impactos da pandemia fazem-se sentir em diferentes segmentos populacionais, particularmente entre aqueles que vivem trabalham e transitam em territórios vulnerabilizados, orientando que essas reflexões voltem-se às pessoas com deficiências. Em diferentes momentos, individual ou coletivamente, pessoas com deficiência têm questionado e se insurgido contra diferentes barreiras - arquitetônicas, atitudinais, socioculturais - que representam obstáculos da expansão de seus territórios existenciais, que segundo Borges (2015) se caracterizam por suas dimensões ético-estéticas.

Ainda que as reformas dos séculos XIX e XX tenham procurado modernizar grandes centros urbanos privilegiando a higiene e a salubridade, ao longo da história encontra-se documentado como as cidades na antiguidade, idade média ou moderna, atravessaram epidemias ou pandemias em virtude do adensamento populacional. Nesse sentido, referindo-se à Pandemia da COVID-19, Medeiros e Rajs (2020) ressaltam que:

[...] A realidade tem mostrado que os riscos e os efeitos catastróficos da doença são desproporcionalmente maiores para as populações vulnerabilizadas, em especial as que vivem em assentamentos informais, favelas, loteamentos, ocupações, bem como a população em situação de rua [...] (p.6).

As autoras (2020), apoiadas em dados do IBGE de 2010, afirmam que “[...]cerca de 11,4 milhões de pessoas viviam em favelas no Brasil. Em Belém (PA), a proporção de população favelada chegava a ser de 54\%; em Salvador (BA), 33\% e no Rio de Janeiro (RJ), 22\% [...]", espaços que além das precárias condições de habilitação e saneamento, sofrem cronicamente com o ausência de políticas do Estado brasileiro.

Em 2020, em meio à Pandemia, deve-se questionar: os indicadores revelam mudanças do ponto de vista quantitativo ou qualitativo da vida das pessoas nas grandes cidades? E o que dizer da vida das pessoas em favelas e periferias? Como situar aspectos de mobilidade urbana no Brasil e na América Latina? Que lições acerca da vida das pessoas com deficiência foram assimiladas no contexto da Pandemia?

As desigualdades sociais observadas que se agigantam em grandes cidades inegavelmente agravam as condições de saúde da população, especialmente se for acrescentado o problema do fornecimento regular de água - essencial à existência 
humana antes, durante e depois da Pandemia. Outra questão é a necessidade de reordenação de espaços ampliando a mobilidade das pessoas com deficiência.

Nesse sentido, ao se refletir ensaísticamente (Meneghetti, 2011) sobre o viver em uma cidade/sociedade capacitista, remete-se à discussão das condições da acessibilidade em favelas e periferias, direitos sem os quais o viver transforma-se em uma abstração em territórios existenciais, a que Borges (2015) refere como:

[...] toda criação conceitual é histórica, contextual e singular, sempre uma singularidade [...] a teoria é a porta de acesso ao engajamento político em um mundo cognoscível, compartilhando territórios existenciais que não se limitem ao 'sobrevoo conceitual' sobre a realidade investigada[...] (p. 108).

Como escopo desse artigo propõe-se reflexões sobre como o viver em cidades capacitistas hostilizam as existências de pessoas com deficiência, segmento populacional que segundo a ONU representa cerca de $15 \%$ da população mundial. Se a UPIAS - Union of the Physically Impaired Against Segregation (1975) consideram a deficiência uma opressão social, o que podemos dizer da arquitetura das cidades contemporâneas? As cidades oprimem pessoas com deficiência porque a maioria expressiva dos seus dispositivos (socioculturais, lazer, como museus, cinemas, teatros) atendem uma visão estreita que concentra em percentuais a justificativa segregacionista.

Por outro lado, ao considerar a "deficiência" como uma "produção social" (Kipen, 2012) afirma que "[...] a imagem que inventamos de completude, de corpo completo, inventa um espelho deformado do corpo incompleto, anormal, inadequado [...] a produção do corpo normal, invenção moderna e dispositivo necessário para pensar a escola, o hospital, a família, as cidades $[\ldots] "$ (p.129).

Assim, ao analisar a cidade/sociedade recaem sobre estas a incompletude de políticas públicas voltadas às pessoas com deficiência. Faltam políticas (educação, saúde, habitação, transporte, lazer, cultura) em que o princípio da equidade se faça presente, garantindo requisitos legais do respeito aos direitos de todos sujeitos que habitam a cidade e, singularmente, a própria sociedade.

As reflexões de Gertner \& Vasconcellos (2020) - que evocam direitos das pessoas com deficiência - encontram-se consagrados em dois documentos. O primeiro, toma por base a Convenção da ONU, implementado como emenda constitucional, a partir do Decreto 6.949 de 25 de agosto de 2009, por meio do qual os Estados Partes devem assegurar: "[...] todas as medidas necessárias para a proteção e segurança de pessoas com deficiência que se encontrarem em situações de risco, inclusive em emergências humanitárias (art. 11) [...].” (p. 22)

O segundo documento, de acordo com Gertner \& Vasconcellos (2020), é a Lei Brasileira de Inclusão da Pessoa com Deficiência (LBI), conhecida como Estatuto da Pessoa com Deficiência (Lei no 13.146, de 06/07/2015), ao estabelecer em seu art. $4^{\circ}$ que toda pessoa com deficiência tem direito à igualdade de oportunidades com as demais pessoas, e não sofrerá nenhuma espécie de discriminação em razão de sua condição. (p.22)

Desta forma, compreende-se que as reflexões "sobre o viver em uma cidade capacitista: antes, durante e depois da Pandemia", título do artigo, não podem ser apartadas dos preceitos que fundamentam a condição de sujeito de direito sanitário de pessoas com deficiência ou com sofrimento psíquico, a ser examinado no próximo segmento.

\section{Metodologia}

O artigo, em forma de ensaio (Meneghetti, 2011), objetiva inicialmente formular reflexões acerca do capacitismo observado em cidades e sociedades contemporâneas, valores que usualmente se fazem presentes na linguagem, nas relações interpessoais e institucionais, espraiando-se na cultura como uma forma de categorização e hierarquização de sujeitos, na maioria das vezes reduzidos a rótulos, deixando de lado sua condição de sujeito de direitos sanitários. 
Nas considerações finais, propõe-se como dois possíveis desdobramentos do ensaio, o primeiro, a realização de uma pesquisa qualitativa (Pereira et al., 2018) no âmbito institucional, trabalhando com o universo de significados, motivos, aspirações, crenças, valores e atitudes, que podem favorecer a compreensão das relações capacitistas interpessoais. Em, segundo lugar, não menos importante, a perspectiva de propor uma intervenção ético-estética (exposição itinerante), em que se materializem conteúdos imagéticos do capacitismo que permeiam o imaginário sociocultural.

3. O "não nosso de cada dia": pessoas com deficiência e os impactos do capacitismo estrutural

Diariamente pessoas com deficiência enfrentam barreiras que lhes inviabilizam o exercício de direitos fundamentais. É como se, todos os dias, a cidade lhes dissesse "não".

Essas experiências reiteradas pela falta de acessibilidade (urbanística, comunicacional, normativa, atitudinal e tecnológica), são validadas por uma cultura capacitista construída ao longo de séculos. A arquitetura hostil nos espaços públicos, a poluição sonora e visual dos centros urbanos, o tratamento compassivo ou a indiferença são formas capacitistas que inviabilizam o pertencimento das pessoas com deficiência como legítimas integrantes de sua comunidade, com os mesmos direitos das demais pessoas.

Frente à experiência de receber tantos "nãos" - que impedem a plena participação das pessoas com deficiência na sociedade-, qualquer pessoa que não tenha contato com os estudos sobre a deficiência - pela perspectiva de direitos humanos é levada a concluir que é seu corpo "defeituoso""’anormal” que lhe limita a existência (Gavério, 2015).

Ser tratado como alguém que é inferior às demais pessoas, ter suas capacidades subestimadas cotidianamente, receber a negativa - no planejamento urbanístico, arquitetônico, comunicacional - de suas especificidades; ser negado em seu jeito particular de falar ou fazer as coisas, requer o esforço de superar a indignação, e até mesmo a raiva, para sujeitar-se ao papel social que deve ser assegurado às pessoas com deficiência na sociedade contemporânea.

Quantas vezes um "Basta!”, um "Chega!” ou um palavrão são proferidos em silêncio por nós? Quantas vezes o estômago se revira ao não permitirem que manifestemos nossas decisões? As reações às violências sofridas nesse cotidiano capacitista são muitas.

Gavério (2015) reflete que essas experiências capacitistas modulam os indivíduos. Segundo o próprio, "o corpo dissonante, exatamente por causar fissuras tão perceptíveis nas expectativas das interações pessoais, acaba por gritar silenciosamente as diferenças."

Nesse sentido, e seguindo a série de "berros engolidos", a resposta a comentários do tipo: "Ah, que pena, teve depressão devido à sua deficiência..."”; pode ser: "Não! Depressão é ter que viver em uma cidade capacitista!".

A força vital dispendida para executar tarefas básicas devido à inacessibilidade; para reagir frente às violências; para superar os impactos das discriminações "naturalizadas"; para contestar normas que pressupõem a existência de um tipo de ser humano universal; o isolamento muito anterior à pandemia formam o "caldo existencial" de quem sobre-vive com deficiência em ambientes hostis.

Muito embora haja estudos acadêmicos sobre a deficiência pela perspectiva do modelo social desde os anos 90 no Brasil, estes não impactaram na formulação de políticas públicas que concebessem as diversidades humanas para que essas alcancem toda a coletividade. São nas cidades que essas políticas públicas chegam, ou deveriam chegar...

No entanto, coerente com os argumentos acima referidos, postula-se nesse segmento que muitas das necessidades das pessoas com deficiência não podem ser negadas apoiadas em percentuais quantitativos, uma vez que as premissas da "arquitetura ou engenharia das cidades capacitistas" precisam ser revistas. Não é crível que o planejamento urbanístico das cidades - arquitetônico ou de engenharia - tome por base o percentual de $15 \%$ da população com pessoas com deficiência como argumento para limitar projetos habitacionais adequados às especificidades desse segmento populacional. 
Pessoas com deficiência não são números ou percentuais, são sujeitos de direitos sanitários. Para esclarecer melhor este conceito ressalte-se que Vasconcellos e Oliveira (2012), constatando que o mesmo não se encontra assegurado na constituição de 1988, apontam que a sua pretensão é que a expressão - sujeito sanitário: "[...] possa servir a um significado de sujeito construtor de sua própria cidadania no âmbito da saúde pública, no caso, como portador de uma cidadania sanitária [...]" (p.3).

Segundo os autores (2012) a palavra sujeito:

[...] fiel à origem latina do termo, o sentido é negativo frente a um senso comum de que escravizar-se, constrangerse, depender, enfim, é negar (negativar) o impulso para a vida, deixar de reagir enquanto ser afirmativo no andar a vida - o sujeito é levado, não leva; o sujeito é impulsionado, não impulsiona [...] ao vincular a palavra à terminologia jurídica, os dicionários mudam-lhe o sentido ao dar-lhe o significado de sujeito enquanto titular de um direito [...] Dispõe-se a retirar-lhe, assim, o estigma semântico de ente passivo para conferir-lhe uma titularidade de direitos [...] A emergência de um novo sujeito, não mais apenas cativo e dócil, mas titular de direitos vai sendo pouco a pouco moldado na nova ordem política e econômica que desaloja o despotismo do século XVIII e inaugura as cartas de novos sujeitos [...] (p.4-5)

Em meio a essa "miscelânea conceitual", expressão adotada por Vasconcellos e Oliveira (2012):

[...] a teoria geral do direito contemporânea ressente-se de uma explicação para a questão: qual o sentido duma equivalência entre pessoa, sujeito de direito e capacidade? As origens dessa relação de equivalência remontam, mais imediatamente, ao pensamento jurídico alemão do século XIX que procurou sistematizar o direito privado ao redor da figura do subiectum iuris como representação do homem livre, dotado de vontade e titular de autonomia [...] (Leonardo, 2010:551-552).

Assim, na perspectiva de Vasconcellos e Oliveira (2012), apoiados em Ferreira (2006) e Salles (2008), o conceito de sujeito de direito sanitário, reafirma que:

[...] o papel do cidadão, longe de ser mero cumpridor de ações ditadas por técnicos e autoridades públicas, é também o de um 'sujeito sanitário', crítico e corresponsável pelo processo coletivo de construção da saúde [...] (p.16).

Os autores (2012), finalmente destacam que ao tratarmos de um 'sujeito sanitário' tratamos de uma migração conceitual, paradigmática, de transformação de alguém, tido como mero objeto das políticas (ancestrais) de saúde, trabalho, habitação, para um outro alguém, sujeito participante, ativo, formulador e observador/fiscalizador de seus próprios direitos.

...o sujeito sanitário na perspectiva do direito tem na expressão uma agregação de valores e significados simbólicos que traduzem suas características e suas credenciais para que o sujeito possa ser assim, ele mesmo protagonista, considerado nas políticas públicas de saúde. (Vasconcellos \& Oliveira, 2012, p. 22) (grifos dos autores)

Desse modo, ao ultrapassar os limites da relação sujeito de direito sanitário para além do campo da saúde, identificase que as perspectivas sobre o viver em uma cidade/sociedade capacitista, depende-se do engajamento individual e coletivo dos sujeitos, ora contrapondo-se às expressões capacitistas, ora adicionando ao "não nosso de cada dia" os direitos básicos inerentes à condição humana na vida em sociedade.

O estímulo de pensar uma espécie de "tour/roteiro/gui" em uma cidade com características (arquitetônicas, políticas, atitudinais, socioculturais, etc) capacitistas não é resultado de uma produção acadêmica, mas fruto de uma inspiração do artista argentino Jorge Macchi que desenhou um mapa de Buenos Aires a partir de diferentes objetos por ele recolhidos naquela cidade. 
Se, todavia, de maneira plástica, inspirados por Macchi fosse proposto uma "instalação" dos símbolos capacitistas de uma cidade atravessados pela poesia de Carmen Vallejo (Nómadas, 1990), estar-se-ia estabelecendo um "roteiro/guia/tour" que se pode sentir no corpo/"anima":

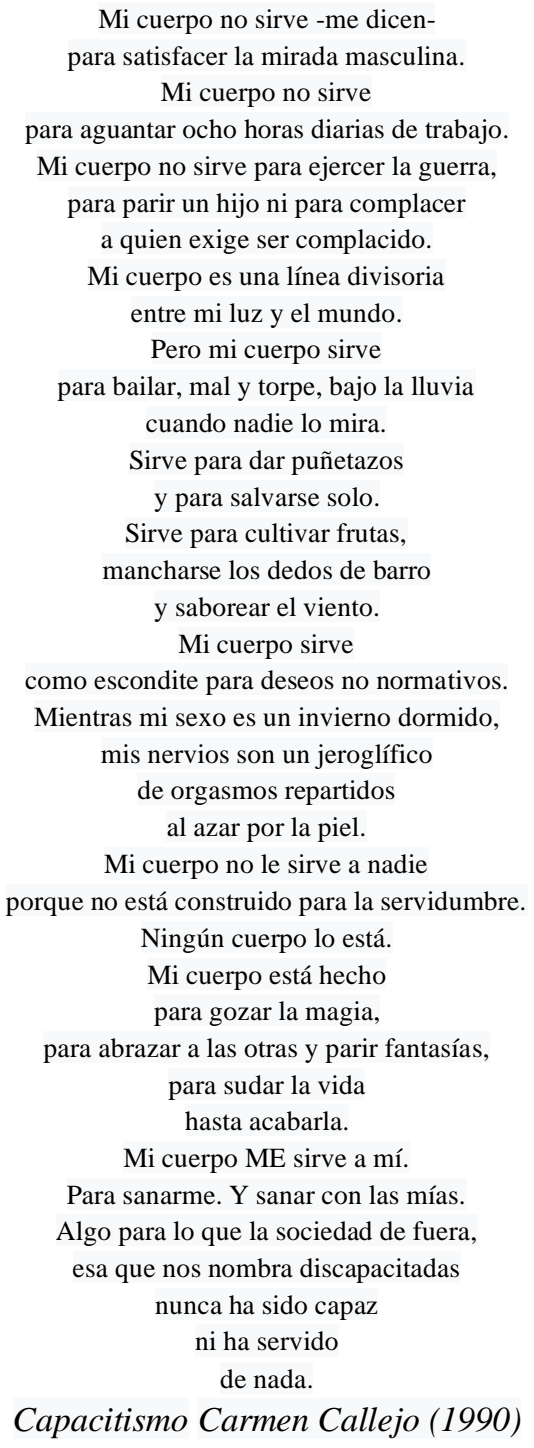

Expostos, todos, a esse "tour" em uma cidade/sociedade capacitista, pergunta-se: que impressões existenciais das pessoas seriam reconhecidas/asseguradas?

Assim, para além do "exercício" cotidiano de ultrapassar as barreiras impostas pelo modelo produtivo de sociedade (Kipen, 2012) - onde até mesmo a inclusão, por vezes, se dá de forma excludente - faz-se necessário outra tipologia de exercício - agora não metafórico - que afirma o locus da existência, da singularidade do direito do sujeito enquanto uma práxis política.

Desta forma, a cada tentativa de anular a presença ou marca existencial da "pessoa com deficiência" ou "sofrimento psíquico" no processo societário, torna-se essencial reafirmar etapas da desconstrução da ideia de "incompletude" e "anormalidade" dos corpos, e servir-se das teorias retratadas no documentário "Crip Camp" (Heumann, 2020) que, na condição de "espelhos" da realidade, revelam que "incompletas" são as cidades/sociedades capacitistas. 


\section{Da Reforma Psiquiátrica à Necropolítica Pandêmica: como lidar com retrocessos?}

A Lei n. 10.216, de 6 de abril de 2001, dispõe sobre a proteção e os direitos das pessoas com transtornos mentais e redireciona o modelo assistencial em saúde mental, instituindo em nosso país o que podemos chamar de Reforma Psiquiátrica Brasileira. Inspirou-se em movimento similar ocorrido na Itália na década de 1970, liderado entre tantos outros por Franco Basaglia, figura símbolo da transformação da Saúde Mental no mundo. Em 13 de maio de 1978, foi aprovada a Lei 180, ou seja a Lei da Reforma Psiquiátrica Italiana, que viria a ser conhecida como Lei Basaglia. Tratava-se da primeira (e ainda única) lei nacional que prescrevia a extinção do modelo manicomial e sua substituição por um conjunto de práticas, princípios e dispositivos substitutivos. A proposição de Basaglia (1991) no livro "A Instituição Negada" foi de colocar entre parêntesis a "loucura" para se ocupar dos sujeitos da experiência, operando uma inversão na lógica psiquiátrica. Demonstrou que, como sujeitos, necessitavam de casa, de trabalho, de amigos, de arte e da cidade. Dessa forma enfrentou os dispositivos manicomiais para desmontá-los. No Brasil serviram de estímulo para que o Movimento de Trabalhadores da Saúde Mental (MTSM) adotasse como insígnia a "luta antimanicomial".

Analisar aspectos históricos da luta antimanicomial é inclinar-se igualmente nas contribuições de Goffman (1961) acerca do perfil asilar das instituições totais (manicômios, prisões, conventos), cujas características peculiares contribuíram significativamente para a estigmatização social da população que ocupava estas instituições. A riqueza de detalhes formuladas por Goffman sobre as instituições totais, determinou que a reforma psiquiátrica implementada no Brasil se deixasse inspirar por estratégias de desconstrução dos aparatos segregacionistas.

Enquanto no passado longínquo a "grande internação" (Foucault, 1987) determinou que delinquentes, loucos, miseráveis, pessoas com deficiência, com hanseníase e tuberculose fossem institucionalizados em espaços "à margem da sociedade", Basaglia e seus seguidores no Brasil, além de se engajarem na luta contra maus tratos e condições desumanas assistenciais, optaram pela lógica da desinstitucionalização e desconstrução gradativa das estruturas manicomiais.

Instituições públicas e privadas passaram a ser objeto de monitoramento e avaliação permanente pelo aparelho do Estado, por vezes dando lugar ao descredenciamento daquelas que serviam-se das autorizações de internação hospitalar (AIH) para manter segmentos populacionais em espaços considerados inapropriados para a assistência psiquiátrica. Em decorrência desse processo de supervisão, contribuiu-se para que novos programas (por exemplo, de Residências Terapêuticas) fossem estabelecidos como uma resposta contra hegemônica de natureza anti-asilar. Verbas que anteriormente eram destinadas a internação de longa permanência, reorientaram o processo assistencial, por um lado opondo-se a segregação social, e, por outro, reintegrando no seio da sociedade, em residências fora do espaço hospitalar, pessoas em sofrimento psíquico.

Portanto, pode-se afirmar que os direitos destes sujeitos sanitários foram resgatados lenta e gradativamente. Espaços hospitalares asilares passaram a se diferenciar: foram criados centros comunitários, espaços de convivência, projetos e programas intersetoriais foram estabelecidos, dando origem posteriormente ao que ficou conhecido como Centros de Atenção Psicossocial (CAPS), que passaram a integrar a Rede de Atenção Psicossocial (RAPS) do aparelho de Estado.

Desta forma, o presente artigo busca destacar que a desconstrução crítico-prática do modelo manicomial serve de base para que se (re)institua a lógica dos direitos da população, de viver e ser acompanhado observando laços de base territorial.

Esse artigo, escrito no momento em que se registra a Pandemia da COVID-19, é atravessado pelo que se denomina de necropolítica, uma vez que medidas anacrônicas (como a referida ao DECRETO 10.502, de 30 de setembro de 2020), estabelecem um retrocesso político-ideológico que configura a volta a um processo de cunho segregacionista, que pode (re)instituir no âmbito da Saúde Mental a lógica superada que manteve à margem da sociedade pessoas (com sofrimento psíquico, pessoas com deficiência). Estamos, mais uma vez, testemunhando um "salto nas sombras de um passado de triste memória"? 
Assim, cumpre ressaltar aqui aspectos que caracterizam a inconstitucionalidade deste decreto porque: viola a proteção de direitos humanos, discrimina e responsabiliza as pessoas com deficiência pelas dificuldades na inclusão escolar; fere diversos preceitos da Convenção Internacional sobre os Direitos das Pessoas com Deficiência e/ou sofrimento psíquico e seu Protocolo Facultativo), que é o único tratado internacional de direitos humanos com status de norma constitucional no Brasil. Os compromissos internacionais assumidos com a referida Ação Direta de Inconstitucionalidade (ADI) 6590 para suspender a eficácia do Decreto 10.502/ 2020, obrigam e estabelecem o sistema de ensino inclusivo em todos os níveis, inclusive a disciplina da Libras nas escolas (Oliveira et al, 2021), bem como consultas estreitas envolvendo ativamente pessoas com deficiência nos processos de tomada de decisão relativos às pessoas com deficiência (artigo 4 da Convenção).

No tocante ao ensino inclusivo, após mobilização social o Supremo Tribunal Federal, em 28/12/20, referendou a Ação Direta de Inconstitucionalidade (ADI) 6590 para suspender a eficácia do Decreto 10.502/ 2020, uma vez que na fala do relator

"o paradigma da educação inclusiva é resultado de um processo de conquistas sociais que afastaram a ideia de vivência segregada das pessoas com deficiência ou necessidades especiais para inseri-las no contexto da comunidade. "Subverter esse paradigma significa, além de grave ofensa à Constituição de 1988, um retrocesso na proteção de direitos desses indivíduos". (STF, 2020).

Embora se considere esta medida uma vitória plural da sociedade que se viu desrespeitada por uma medida disfarçada de política de inclusão, não é possível descansar, mas continuar na luta contra a pratica do negacionismo aos direitos das pessoas com deficiência (e/ou sofrimento psíquico) da segregação social.

\section{Pessoas como Textos \& Cidades como Corpos: e o que dizer da sociedade?}

Ao pensar na metáfora de Gergen (2007) de pessoas como textos, em contínua "leitura/releitura por "outros textos" que circulam na cidade, apoia-se em Campos \& Matiz (2017), quando se pretende confiar que “[...] as transformações venham com justiça epistêmica, redistribuição econômica, reconhecimentos ontológicos e restauração ecológica [...], como proposta na apresentação da Nómadas.

Nesse sentido, tomando emprestado a metáfora gergeniana de pessoas como textos, assume-se que as "cidades" podem representar figurativamente um espaço em que, seguindo a lógica de Gergen (2007), estão presentes textos incluídos em livros (do inglês TEXTBOOK). As "cidades" e as histórias das pessoas com deficiência devem ser registradas nesse enorme "acervo de textos", alguns mais rebuscados outros bem mais simples.

Assim, se as pessoas tomam forma de "textos" registrados historicamente em "livros", o que dizer da sociedade? Que princípios e valores "editoriais" têm regido todas estas relações "intertextuais"?

Pode-se afirmar que a contemporaneidade reserva proximidade entre pessoas como texto e cidades como "livros" em uma "trama" tecida coletivamente? Resistiria a "sociedade" a uma análise das ciências sociais críticas do par de oposição inclusão versus exclusão? Quais os impactos de serem ocultos/excluídos "textos"/"livros" em nossas "cidades"? Que conhecimento pode contribuir para a transformação de "cidades/sociedades" capacitistas?

É inegável de que a invisibilidade de "pessoas como texto", estigmatizadas como "deficientes", "loucas", "autistas", mantêm uma forma de censura prévia à sua existência nas cidades e na sociedade em geral. Este tipo de fenômeno é resultado da difusão na cultura de terminologias encontradas no DSM, enclausurando-as em taxonomias do déficit (Gergen, 1992; Amorim, 1997; Ramos, 2014; Lima, 2014; Amorim, Gertner, Amorim, 2018) essencialistas.

Grande parte das expressões capacitistas utilizadas contemporaneamente decorrem do complexo-médico-acadêmicoindustrial (CMAI), que desde há muito transforma sujeitos em objetos do discurso, tornando a sociedade e a cultura progressivamente enferma (Gergen, 1990). 
Os "efeitos colaterais" da "classificação terminológica" é sentida simbólica e existencialmente em territórios existenciais ético-estéticos" (Borges, 2015) de pessoas rotuladas como "doentes mentais", "deficientes", e afetam sua intersubjetividade. Ou melhor seria dizer sua intertextualidade social?

O linguista Blikstein (1992) demonstrou que nos "corredores semânticos" da linguagem fabricada continuamente pelo CMAI - estão contidas valências positivas ou negativas que acabam por determinar marcas simbólicas nas existências das pessoas caracterizadas por constructos sociais da linguagem do déficit (Gergen, 1990; Amorim, 1997).

Em sendo assim, torna-se necessário que um "determinado texto" materialize a descrição de "um lugar epistêmicopolítico para viabilizar condições de vida e reclamar direitos, como possibilidade de construir multiplicidade, pluridiversidade e heterotopias", como expresso na poesia anti-capacitista de Carmem Callejo (1990), que em trecho final afirma:

\author{
“[...] Mi cuerpo ME sirve a mí. \\ Para sanarme. Y sanar con las mías. \\ Algo para lo que la sociedad de fuera, \\ esa que nos nombra discapacitadas \\ nunca ha sido capaz ni ha servido de nada.[...]"
}

Recomenda-se, pois, que "textos" anti-capacitistas, como o de Carmem Callejo (1990), sejam "lidos de dentro para fora", como devem ser lidos todos os "textos" para que "os livros", como acervo de todos que existem nas cidades, traduzam fielmente um retrato da sociedade com pluridiversidade, rompendo a corponormatividade - imposta de fora -, e que, à priori, censura "textos considerados imperfeitos".

Se forem ampliados olhares para além do limite e conteúdo dos "livros" e "cidades:, observar-se-ão "estados" e "países", que mais à frente, haverão de requerer a "exumação" e conceitos do biopoder, que ainda hoje insistem em classificar hierarquicamente pessoas com diversas categorias que derivam da lógica capacitista ainda presente na cidade/sociedade. Se forem examinados com o devido cuidado, "pessoas como texto" transitam entre cidades, países e continentes onde a diversidade se faz presente.

Algumas dessas experiências representam narrativas do self , mas insiste-se na metáfora de "pessoas como textos" compondo um grande acervo social, ora sob a forma de enfrentamento de suas condições humanas - sofrimento psíquico; estigmatização pela categoria do déficit -, ora a partir de expressões ético-estéticas - que derivaram de trajetórias de luta; por meio da advocacia-em-causa-própria -, ora distanciando-se de representações que lhes foram atribuídas ("doentes mentais", “deficientes”) a partir de um outro locus ou território existencial, quando alguém muda a trajetória (pré)concebida pelo biopoder e por sua autodeterminação assume outro rumo para sua vida.

Assim, se uma determinada pessoa narra-se como texto, cada uma das pessoas que o lêem podem fazê-lo de maneiras diversas, porque as interpretações do texto lido/sentido/vivenciado poderão variar dependendo do acervo que constituem as vivências de quem lê. Desta forma, se alguém escolhe abandonar a forma textual da pessoa "como sofrimento psíquico", passando a descrever-se como artista, um novo mundo se descortina de "dentro pra fora", porque a arte transforma as relações sociais.

A isso Avelino (2018), baseado no pensamento político de Foucault, chama de produção de subjetividade. Abandonase, pois, a "marca do destino" e assume a demarcação de um novo território existencial ético-estético na Saúde Coletiva (Borges, 2015).

Assim, tenta-se responder o questionamento acerca da sociedade em que se vive. Deve-se admitir que as políticas públicas (saúde, educação, trabalho, lazer, cultura, habitação, transporte, dentre tantas outras) são formuladas a partir de um quantitativo/percentual de "pessoas consideradas como normais/perfeitas". Entende-se, assim, a sociedade com seu perfil 
exclusivista/segregacionista, motivo pelo qual os dispositivos/políticas de habitação, transporte, trabalho, por exemplo, comportam-se como se não vissem que existem outras pessoas com certas especificidades.

Esse "jogo de faz de conta" de que não existem pessoas com especificidades, dão passagem ao que procuramos abordar como parte do "não nosso de cada dia". Desta forma, considera-se que a cada apartamento construído onde o desenho universal não seja contemplado deve corresponder a protestos veementes dos "textos censurados".

Em outras palavras, o trecho da poesia anticapacitista da Carmen Callejo ("o meu corpo me serve a mim") é um alerta de que as cidades/sociedades sejam pensadas por todos e para todas as pessoas que nelas vivem, estudam, trabalham e moram. Logo, pensar sobre o viver contemporâneo é também saber reconhecer o rebelar-se contra diversos ditames (bio)capacitistas, que normatizam o planejamento urbano, usualmente voltado para a maioria de "corpos perfeitos" que cabem no modus faciendi da arquitetura e engenharia moderna.

Trazemos para a cena fragmento do texto de Oliveira, Navarini e Aydos (2017) que aponta possíveis novos caminhos sobre o viver em uma cidade/sociedade capacitista:

[...] Aleijar as práticas é reconhecer as responsabilidades éticas, epistêmicas e políticas do questionamento de todas as condições preexistentes sob as quais todos nós vivemos; é perceber que esse aleijamento beneficia também àqueles que não estão interessados ou investidos nessa transformação. Talvez o contexto atual da pandemia estique o tecido social até a ruptura dos modos de vida habituais, talvez refletir a partir da Teoria Crip nos mostre um caminhar torto, no qual o capacitismo deixe de ser o modelo a ser mimetizado, para que outros andares sejam possíveis e mais corpos apareçam $[\ldots]$ (p. 5)

Assim, justifica-se o "não nosso de cada dia", como no livro "Being Heumann" --- que explora a sonoridade de "ser humano" (being human) --- como provocação às barreiras atitudinais de comportamentos societários que à priori continuam a estigmatizar, fazendo da "cidade" (repletas de "livros" a serem lidos) o lugar planejado para a maioria de "corpos idealmente perfeitos". Do "outro lado da cidade", os "textos censurados" continuam a viver enclausurados/excluídos em "guetos", sem acesso a museus, teatros, espaços de lazer e trabalho, e acima de tudo de moradias que atendam suas especificidades.

A perspectiva ensaística conforme postulada por Meneghetti (2011), resguarda que "[...] no ensaio a orientação é dada não pela busca das respostas e afirmações verdadeiras, mas pelas perguntas que orientam os sujeitos para as reflexões mais profundas [...]" (p.321)

Dessa forma, pergunta-se: que tarefas estão reservadas aos coletivos anticapacitistas? Que contribuições pessoas com deficiência podem trazer para a transformação da realidade capacitista? Essas questões são examinadas no próximo segmento.

\section{Eu na Primeira Pessoa do Singular \& Nós como Parte da Sociedade/Cidade}

Sobreviver em meio à negação do território existencial requer o exercício cotidiano de natureza política. A resiliência de ontem arrefeceu, abre caminho e, muitas vezes, dá lugar a variados sentimentos -- frustração, raiva, tristeza, invisibilidade -mas ao mesmo tempo, em meio à pandemia, se intensifica e se coletiviza quando se percebe que não se está sozinho, momento em que a primeira pessoa do singular se transforma em nós, a primeira do plural..

Devido ao virar dos olhos de quem não quis me/nos enxergar e me/nos discriminou ontem/anteontem. Hoje e sempre aprende-se a engolir a seco os berros não dados, ora por conta da timidez, ou orgulho, de quem não quer mais ser visto como "inconveniente". O "bicho estranho na selva de cimento", dá passagem a militância, ao coletivo que brada aos quatro cantos sobre o viver na sociedade/cidade, ainda que ainda capacitista.

Apoia-se em Vendramin (apud, Dias, 2013) para afirmar que: 
“[...] os elementos estruturantes do capacitismo são decorrentes do histórico de eugenia sofrido pelas pessoas com deficiência, das implicações da normatização e, de forma mais recente, da ofensiva do neoliberalismo [...] Está relacionado a uma compreensão normatizada e autoritária sobre o padrão corporal humano, que deflagra uma crença de que corpos desviantes serão consequentemente insuficientes, seja diminuindo seus direitos e mesmo o direito à vida em si, seja de maneira conceitual e estética [...]" (p. 2)

No entanto, o meu/nosso(s) corpo(s) ocupando espaços públicos é bandeira hasteada contra o capacitismo, rompendo o isolamento imposto pela opressão diária de cada dia, transformando a solidão e a dor, em uma oportunidade de coletivização de um justo movimento anti-capacitista permanente. Chega de fazer de conta que não se está aqui como cidadão, pois incompleta e imperfeita é a cidade e a política que não me/nos contempla, e a sociedade idealizada pela perfeição de inspiração secular.

Há, pois, que se desafiar, em transformar-se em luta tantas vezes, por tantos dias, meses, anos. Chega de ser paciente e forte ao ouvir dizer que "a nossa existência requer caridade" e, (im)pacientemente ter que explicar que não se trata disso, do apoio especializado, nem tampouco de instituições que abracem nossas imperfeições, e as aproximem de um "ideal estético", que francamente mais nos parecem o retorno de um "pesadelo eugênico". Ou, seria o retorno da "guerra das raças" denunciada por Foucault (2015)?

Nesse sentido, opta-se pela coletivização que refletir sobre o viver e habitar uma cidade, a sociedade de maneira geral, é ocupar os principais prédios e ruas insuficientemente acessíveis; bloqueando principais vias de acesso pela via "cripcampiana"(https://encenasaudemental.com/cinema-tv-e-literatura/quando-ocorre-uma-verdadeira-revolucao-pelo-principio-dainclusao/) e a circulação no centro das cidades com uma "instalação" de cadeiras de rodas, próteses, órteses. Se somente nos vêm da forma "ideal", passarão a nos enxergar como "obstáculos políticos", como existências de sujeitos de direitos sanitários (Oliveira e Vasconcellos, 2012) que lutam por lazer, cultura, habitação, transporte, em que as dimensões de acessibilidade e inclusão não são concessões do Estado, mas questões de princípio das quais não se abre mão em forma de luta.

\section{Considerações Finais}

$\mathrm{O}$ artigo, ensaisticamente organizado, desafia o capacitismo a partir de uma perspectiva singular e plural sobre o viver na cidade/sociedade atravessada por elementos que estruturam continuamente os modos de ver e ocultar os corpos das pessoas que vivem, trabalham, estudam e circulam nestes espaços públicos e privados.

Os questionamentos e reflexões produzidos aqui a partir de perspectivas desnaturalizadoras de visões capacitistas, devem possibilitar novos territórios existenciais ainda por explorar, ora por meio de uma pesquisa qualitativa no ambiente institucional e sob a forma de intervenção artístico-cultural, que expresse, ético-esteticamente, formas imagéticas de questionamento do capacitismo estrutural em cidades e sociedades contemporâneas.

Restam as tarefas de ocupar as cidades e proporcionar à sociedade "roteiros/tour" anticapacitistas que se oponham à corponormatividade, mediados permanentemente por meio da diversidade de olhares e o não nosso de cada dia.

\section{Referências}

Borges, S.A.C.(2015). Territórios existenciais ético-estéticos em saúde coletiva. Fractal, Rev. Psicol. [online], $27(2), 107-113$.

Medeiros, A.P; \& Rajs, S. (2020). As Cidades e a Pandemia: Efeitos, desafios e transformações. In: Diálogos sobre acessibilidade, inclusão e distanciamento social: Territórios Existenciais na Pandemia, IdeiaSUS, Fiocruz, p. 6-9.

Meneghetti, F. K. (2011) O que é um Ensaio Teórico? In: RAC, Curitiba, 15(2) Mar./Abr. RAC, Curitiba, ANPAD, pp. 320 -332. 
Research, Society and Development, v. 10, n. 2, e6810212294, 2021

(CC BY 4.0) | ISSN 2525-3409 | DOI: http://dx.doi.org/10.33448/rsd-v10i2.12294

UPIAS - Union of the Physically Impaired Against Segregation (1975) Fundamental Principles of Disability. Site: https://the-ndaca.org/resources/audiodescribed-gallery/fundamental-principles-of-disability/

Kipen, E. (2012). En torno a una conceptualización -(im)posible- de la discapacidad. In: Debates y perspectivas en torno a la discapacidad en America Latina, (Maria Eugenia Almeida \& Maria Alfonsino Angelino, comp), p. 128-132.

Gertner, S.R.C.B.; \& Vasconcellos, L.C.F. (2020). Trabalho, inclusão e acessibilidade no pós-pandemia: para onde vamos? In: Diálogos sobre acessibilidade, inclusão e distanciamento social:Territórios Existenciais na Pandemia,IdeiaSUS, Fiocruz, p.6-9.

Pereira A.S. et al. (2018). Metodologia da pesquisa científica. [e-book]. Santa Maria. Ed.UAB/NTE/UFSM. https://repositorio.ufsm.br/bitstream/handle/1/15824/Lic_Computacao_Metodologia-Pesquisa-Cientifica.pdf?sequence=1 .

Gavério, M. (2017). Nada sobre nós, sem nossos corpos! O local do corpo deficiente nos Disability Studies. Revista Argumentos, Montes Claros, 14(1), 95117 , jan/jun.

Vasconcellos, L.C.F.; \& Oliveira, M.B.H. (2013). O sujeito sanitário na perspectiva do direito, p. 27-52, In: Direito e Saúde: Cidadania e Ética na Construção de Sujeitos Sanitários, EDUFA.

Vallejo, C. (2020). Poesia-Nómadas Estudios ríticos latinoamericanos en discapacidad/ Enero - junio - Argentina - Colombia.

Basaglia, F. (1985). A Instituição Negada, Graal.

Goffman, E. (1961). Asylums: Essays on the social situation of mental patients and other inmates. NJ: Garden City.

Foucault, M. (1987). A História da Loucura, SP: Perspectiva.

Oliveira, A. B. R., Moura, G. B., Cirino, C. S. ., Santos, W. S. ., \& Diniz, Ércules L. . (2021). Representaç̃es sociais da Libras como disciplina obrigatória por atores de escola pública e privada no Munícipio de Guarabira-PB. Research, Society and Development, 10(1), e21110111549. https://doi.org/10.33448/rsdv10i1.11549

STF. Imprensa do Supremo Tribunal Federal. Em 28/12/020, Link: http://www.stf.jus.br/portal/cms/verNoticiaDetalhe.asp?idConteudo=457869

Gergen, K.J. (1990). Therapeutic Professions and the Diffusion of Deficit, In: The Journal of Mind of Behavior.

Campos \& Matiz (NOMADAS). (2017). (Estudios críticos latinoamericanos en discapacidad/Enero - junio - Argentina - Colombia), p.7.

Gergen, K.J. (1988). If persons are texts. Hermeneutics \& Psychological Theory NJ: Rutgers Univ Press, p 18-51.

Amorim, A.C. (1997). "O Espetáculo da Loucura" - Alienismo Oitocentista ... Psiquiatria do III Milênio: A Construção Social da Linguagem do Déficit e a Progressiva Enfermidade da Cultura, Dissertação, UERJ.

Ramos, F. (2014). Do DSM III ao DSM-5: Traçando o percurso médico-industrial da Psiquiatria de Mercado. In: A Criação de Diagnósticos na Psiquiatria Contemporânea, Garamond.

Lima, R.C. (2014). O DSM entre a Novilíngua e a Língua Tertii Imperii. In: A Criação de Diagnósticos na Psiquiatria Contemporânea, Garamond.

Amorim, A C; Gertner, S R; \& Amorim, L A. (2018). Cartografia Histórico-Conceitual da "deficiência": Construção Social feita de “invisibilidades/visibilidades” e de Utopias, In: Uma Ponte ao Mundo - Cartografias Existenciais da Pessoa com Deficiência e o Trabalho, KELPS: Goiânia.

Blikstein, I. (1995). Kaspar Hauser ou A Fabricação da Realidade. Cultrix.

Avelino, N. (2018). Introdução: pensar a política com Foucault. In: O Pensamento Político de Michel Foucault, Intermeios.

Oliveira, B; Navarini, D; \& Aydos, V. (2020). “O que a experiência do Covid-19 nos diz sobre deficiência, trabalho e acessibilidade?” Boletim Cientistas Sociais, ANPOCS. http://anpocs.org/index.php/publicacoes-sp-2056165036/boletim-cientistas-sociais/

Vendramin, C. (2019). Repensando Mitos Contemporâneos: O capacitismo. In: https://www.publionline.iar.unicamp.br/index.php/simpac/article/view/4389

Foucault, M. (2013). Microfísica do Poder. (27a Ed). Graal.

Heumann, J. (2020) EnCena (Link: https://encenasaudemental.com/cinema-tv-e-literatura/quando-ocorre-uma-verdadeira-revolucao-pelo-principio-dainclusao/) 